\title{
To treat, or not to treat, that is the question: Critical review of brain AVM surgery, surgical results and natural history in 2017 by Michael Morgan et al.
}

\author{
Karl Schaller $^{1} \cdot$ Hans-Jakob Steiger ${ }^{2}$
}

Received: 8 May 2017 / Accepted: 9 May 2017 /Published online: 19 May 2017

(C) Springer-Verlag Wien 2017

This extensive review of the results of surgical management of cerebral arteriovenous malformations (bAVMs) as compared to sole observation comes from one of the most experienced groups of AVM surgeons, who have made seminal contributions to the understanding of AVM pathophysiology throughout the past three decades.

In analyzing angioarchitectural features and the natural evolution of AVM in large observational patient series, Morgan et al. arrive at the affirmation of what most neurovascular surgeons are using as criteria to judge an AVM's risk for rupture for many years already. However, rarely it has been written so clearly and rarely was it based on such hard data from longitudinal observational studies. In fact, this teaches us a lot about the potential danger of certain AVM. It is obvious that not all unruptured AVM should be treated (surgically). It is not that simple, and experienced and thoughtful neurosurgeons do not use such simplistic views either. But those patients, whose AVM are classified as Ponce A, will do a lot better when undergoing removal of that AVM rather than letting the natural course decide over the patient's fate. Especially in the presence of deep venous AVM drainage and/or eloquent AVM location the natural risk for rupture amounts to 35-38\% within 8 years of simple observation! Some unicentric and retrospective clinical series have shown that already [1-5], but with their detailed analysis

Karl Schaller

karl.schaller@hcuge.ch

1 Department of Neurosurgery, Faculty of Medicine, University of Geneva, Geneva, Switzerland

2 Department of Neurosurgery, Heinrich-Heine University, Düsseldorf, Germany of potential risk factors for rupture, the authors provide further evidence for those doctors who are involved in the decisionmaking process when it comes to patient counseling, which should be based on hard facts rather than on gut feelings, of course. Therefore, they provide an analysis of existing tools to assess the rupture risk of AVM by a simple mathematical formula, and clinical tools, such as the Spetzler-Ponce classification, or the more recently introduced Lawton-Young score for the estimation of surgical risk. Altogether, they are liberating us in a scientifically sound manner from the myths of the ARUBA study. That study has never examined the results of surgical treatment of cerebral AVM, but is falsely taken as the main reference in favor of conservative treatment by so many not only neurologists and GPs but by many of the young generation of neurosurgeons as well. If there is something the neurosurgical community has to be blamed for, then it is the fact that we have never reached out to a wider community with our efforts to report the good results that can be achieved by surgical removal of certain AVM as compared to a waitand-see strategy. We have never achieved to launch a highlevel RCT on surgical vs. conservative treatment of cerebral AVM. Nobody else, except ourselves, the neurosurgical community, can be accused for the fact that we have let others with lesser understanding and expertise in the field of cerebral AVM influence the opinion of a wider medical community - by journal impact factor rather than by evidence - and to conduct a study, which had lead to fundamental and equally dangerous misconceptions of the risk harboring a cerebral AVM. It was neurologists who have launched that RCT, which is now mistaken to represent an argument against surgery, and which by its solely impact-driven evidence is now endangering hundreds of patients every year with newly diagnosed Ponce class A AVM who might benefit from surgery. It is the merit of Michael Morgan and his team that they provide us with an important accumulation of hard data in favor of 
surgical management of those AVM, and to remind us of our responsibility to provide this information to patients and their relatives - and to the community of clinical neuroscientists involved in their management.

\section{References}

1. Bervini D, Morgan MK, Ritson EA, Heller G (2014) Surgery for unruptured arteriovenous malformations of the brain is better than conservative management for selected cases: a prospective cohort study. J Neurosurg 121:878-890

2. Moon K, Levitt MR, Almefty RO, Nakaji P, Abuquerque FC, Zabramski JM, Wanebo JE, McDougall CG, Spetzler RF (2015)
Safety and efficacy of surgical resection of unruptured low-grade arteriovenous malformations from the modern decade. Neurosurgery 77:948-953

3. Potts MB, Lau D, Abla AA, Kim H, Young WL, Lawton MT (2015) Current surgical results with low-grade brain arteriovenous malformations. J Neurosurg 122:912-920

4. Schramm J, Schaller K, Esche J, Boström A (2017) Microsurgery for cerebral arteriovenous malformations: subgroup outcomes in a personal series of 288 cases. J Neurosurg 126: 1056-1063

5. Steiger HJ, Fischer I, Rohn B, Turowski B, Etminan N, Hanggi D (2015) Microsurgical resection of Spetzler-Martin grades 1 and 2 unruptured brain arteriovenous malformations results in lower long-term morbidity and loss of quality-adjusted life-years (QALY) than conservative management-results of a single group series. Acta Neurochir 157:1279-1287 